\title{
Preoperative heart failure in the Medicare population undergoing mitral valve repair and replacement: An opportunity for improvement
}

\author{
Christina M. Vassileva, MD, ${ }^{\mathrm{a}}$ Naseem Ghazanfari, MD, ${ }^{\mathrm{b}}$ Stephen Markwell, MA, ${ }^{\mathrm{a}}$ \\ Theresa Boley, MSN, ${ }^{a}$ and Stephen Hazelrigg, MD $^{\mathrm{a}}$
}

\begin{abstract}
Background: Elderly patients are under-represented in most surgical series of mitral valve surgery. The impact of preoperative heart failure (HF) on the outcomes of this subset has not been extensively studied.
\end{abstract}

\begin{abstract}
Methods and results: The study included 45,082 Medicare beneficiaries who underwent primary isolated mitral valve repair (MVP) $(n=16,850)$ or replacement (MVR) $(n=28,232)$ from 2000 to 2009. Medicare claims from the year before and the year of the index hospitalization were reviewed for documentation of HF to examine the operative mortality and long-term survival of patients with and without preoperative HF. Preoperative HF was present in $52.5 \%$ and $64.8 \%$ of patients who underwent repair and replacement, respectively. Duration of HF greater than 3 months was present in a significant proportion of patients (18.2\% for MVP and $22.7 \%$ for MVR). Adjusted operative mortality was higher for patients with preoperative HF (MVP odds ratio [OR], 1.46; 95\% confidence interval [CI], 1.21-1.78; MVR OR, 1.36; 95\% CI, 1.23-1.51). Patients without preoperative HF had better long-term survival (MVP hazard ratio [HR], 2.23 [95\% CI, 2.09-2.36]; MVR HR, 1.80 [95\% CI, 1.73-1.86]). After adjustment, a preoperative HF diagnosis was still associated with $52 \%$ and $36 \%$ increased risk of death over the 10-year follow-up period for patients who underwent MVP and MVR, respectively. Preoperative HF duration greater than 3 months conferred an excess $28 \%$ higher risk of death on long-term follow-up compared with patients with HF less than 3 months.
\end{abstract}

Conclusions: Preoperative HF is present in a large number of elderly patients undergoing primary isolated mitral valve surgery and adversely affects their short-term and long-term survival, irrespective of procedure type (repair or replacement). The study supports the early identification of elderly patients with mitral valve disease and referral to surgery before the onset of HF. (J Thorac Cardiovasc Surg 2014;148:1393-9)

The incidence of valvular heart disease was once believed to be declining as a result of decreased incidence of rheumatic heart disease, but degenerative valvular disease has become highly prevalent in the developed world with the rapidly increasing aging population. ${ }^{1}$ For example, the prevalence of mitral regurgitation (MR) in the general population is $1.7 \%$ but this increases substantially with age and affects $9.3 \%$ of adults older than 75 years of age. ${ }^{1}$ Nevertheless, the management of mitral valve (MV) disease in the elderly remains an area of major controversy.

The established benefits of early surgical intervention in preventing left ventricular dysfunction and significant improvement in outcomes have led to the development of guidelines that support early intervention in general, but current American College of Cardiology (ACC)/American

\footnotetext{
From the Department of Surgery, ${ }^{\mathrm{a}}$ Internal Medicine, ${ }^{\mathrm{b}}$ Southern Illinois University School of Medicine, Springfield, Ill.

Disclosures: Authors have nothing to disclose with regard to commercial support.

Received for publication Aug 1, 2013; revisions received Oct 14, 2013; accepted for publication Dec 5, 2013; available ahead of print Feb 7, 2014.

Address for reprints: Christina M. Vassileva, MD, Division of Cardiothoracic Surgery, Department of Surgery, Southern Illinois University School of Medicine, 701 N First St, Rm 319, PO Box 19638, Springfield, IL 62794-9638 (E-mail: cvassileva@siumed.edu).

$0022-5223 / \$ 36.00$

Copyright (c) 2014 by The American Association for Thoracic Surgery

http://dx.doi.org/10.1016/j.jtcvs.2013.12.010
}

Heart Association (AHA) guidelines still advise reserving surgery only for severely symptomatic elderly patients. ${ }^{2}$ These contradictory recommendations mainly stem from reported mortality rates of the elderly undergoing MV surgery exceeding $14 \%$ and as high as $20 \%$ in low-volume centers. ${ }^{2}$ However, the data from these studies mostly reflect combined coronary artery bypass grafting (CABG) and MV surgery. Moreover, these outcomes come from an era when MV repair was performed less frequently. More recent studies have shown a significant decline in morbidity and mortality among the elderly. In a large nationwide study of Medicare beneficiaries with a median age of 75 years who underwent primary isolated MV surgery between 2000 and 2009, Vassileva and colleagues ${ }^{3}$ demonstrated operative mortality for isolated MV repair to be as low as $3.9 \%$ and that of MV replacement to be $8.9 \%$, which is substantially lower than previously reported data.

Delaying surgical intervention for MV disease has several consequences. The development of heart failure (HF) in this setting is predictive of poor outcome, even after surgical correction. Within the elderly patient subset, which is already characterized by higher surgical risk because of the frequent coexistence of associated comorbidities, the presence of HF, a potentially preventable occurrence, further contributes to worse surgical outcomes. We sought to quantify the impact of HF on the outcomes among elderly 


$\begin{aligned} & \text { Abbreviations and Acronyms } \\ & \text { AHA }=\text { American Heart Association } \\ & \text { BASF }=\text { Beneficiary Annual Summary Files } \\ & \text { CABG }=\text { coronary artery bypass grafting } \\ & \text { CI }=\text { confidence interval } \\ & \text { CMS }=\text { Centers for Medicare and Medicaid } \\ & \text { Services } \\ & \text { COPD }=\text { chronic obstructive pulmonary disease } \\ & \text { ESRD }=\text { end-stage renal disease } \\ & \text { HF }=\text { heart failure } \\ & \text { HR }=\text { hazard ratio } \\ & \text { IQR }=\text { interquartile range } \\ & \text { LOS }=\text { length of stay } \\ & \text { LV }=\text { left ventricular } \\ & \text { MEDPAR }=\text { Medicare Provider Analysis and } \\ & \text { Review } \\ & \text { MV }=\text { mitral valve } \\ & \text { MVP }=\text { mitral valve repair } \\ & \text { MVR }=\text { mitral valve replacement } \\ & \text { NYHA }=\text { New York Heart Association }\end{aligned}$

patients undergoing MV surgery before and after the clinical symptoms of HF ensued. Here, we report and compare the operative mortality and 10-year survival of a large cohort of Medicare beneficiaries with and without a preoperative diagnosis of $\mathrm{HF}$ at the time of undergoing primary isolated MV surgery.

\section{METHODS}

The data for this analysis were obtained from the Center for Medicare and Medicaid Services and included the Medicare Provider Analysis and Review (MEDPAR) files and corresponding Beneficiary Annual Summary Files (BASF) for all Medicare beneficiaries aged 65 years and older who underwent mitral valve repair (MVP; ICD-9 code 35.12) or replacement (MVR; ICD-9 codes 35.23 or 35.24) from 2000 to 2009. The MEDPAR files contain institutional claims for inpatient services covered under Part A. The BASF contain information on patient demographics, eligibility, enrollment, summarized service utilization and payment, and chronic condition flags for eligible beneficiaries. The current Vital Status File (February 2012) was used to provide the most recent death information for the study cohort. The study was approved by the Institutional Review Board, which waived the requirement for informed consent. Because the files used for this study are considered Research Identifiable Files and contain patient-specific information, beneficiary confidentiality data was protected through a rigorous data use agreement with Centers for Medicare and Medicaid Services (CMS).

\section{Exclusion Criteria}

Patients were excluded if they had concomitant $\mathrm{CABG}$, other valvular repair or replacement (except tricuspid), closed heart valvuloplasty, surgery for congenital anomalies, heart transplant, awaiting organ transplant status or history of heart transplant, history of surgery to heart and great vessels, history of valve replacement, history of CABG, history of previous myocardial infarction, left ventricular, right ventricular, or biventricular circulatory support implantation or removal, implantation of an external cardiac support device, history of ventricular assist device or artificial heart, excision of ventricular aneurysm, replacement of thoracic aorta, aortic fenestration, or concomitant carotid endarterectomy (same hospitalization). Patients with missing gender information, unspecified valve repair or replacement, Medicare status codes 20 (disabled without end-stage renal disease [ESRD]), 21 (disabled with ESRD), and 31 (ESRD only, not aged), and emergency admission status, as well as those who were recorded as having had MVP and MVR during the same hospital stay, were also excluded from the analysis. Patients were also excluded if they did not have 12 months of Medicare Part A and Part B coverage in the year preceding their operation or if they had a period of enrollment under a Medicare-managed plan at any point in the year before their index admission. Urgent admission status was defined as those patients who were operated on during the same hospital stay; elective admission was defined as those who came from home and were operated on the same day. For the purposes of exclusion, emergency admissions were defined as those patients who were operated on the same day of admission if they were transferred from a hospital, skilled nursing facility, another health care facility, or came through the emergency room.

\section{Definitions and Outcomes}

This study is a descriptive analysis of operative mortality and long-term survival of elderly patients undergoing primary isolated MV surgery according to history and duration of preoperative HF diagnosis. Operative mortality was defined as hospital mortality or 30-day mortality, whichever was longer. Long-term survival was calculated using data from the Vital Status File and reflects all-cause mortality. Comorbidities were determined using the ICD-9-CM diagnostic codes from both the index admission and any hospitalizations during the 12-month period before the index admission.

\section{Statistical Analysis}

All results are reported as median and interquartile range (IQR) or percentages as appropriate. Chi-squared tests of independence and Wilcoxon rank sum tests were used to compare patients with and without preoperative HF. Comparisons were performed across all patients and separately for the repair and replacement subgroups. Groups were initially compared on hospital mortality using chi-squared and then logistic regressions were performed to adjust for baseline differences. Postoperative survival time was computed using the Vital Status File from CMS. Kaplan-Meier estimates were used to generate survival curves for patients with and without a preoperative history of HF. Log-rank tests were used to assess group differences on survival curves. Cox proportional hazards models were used to compare the groups on long-term survival after adjusting for baseline differences. All analyses were performed using SAS v9.2 or v9.3 (SAS Institute, Inc, Cary, NC). Expected mortality rates were calculated using the National Vital Statistics Reports (2007) from the Centers for Disease Control and Prevention. ${ }^{4}$ These rates reflect the expected mortality, based on the US population, within our patient subsets when adjusting for age and gender distribution

\section{RESULTS \\ Patient Characteristics}

The patient characteristics of the study cohort have been described previously. ${ }^{3}$ Briefly, 45,082 patients were identified who underwent isolated MV surgery from 2000 to 2009 (Table 1). MVR was performed in $62.6 \%$ and the remaining $37.4 \%$ underwent MVP. Median age of the patients was 75 years; $61.4 \%$ of the patients were women and $91.8 \%$ were white. Sixty percent of the patients had a diagnosis of HF in the year preceding the surgery, including 
TABLE 1. Baseline characteristics of the study cohort

\begin{tabular}{|c|c|c|c|c|c|c|c|c|c|c|}
\hline \multirow[b]{2}{*}{$\begin{array}{c}\text { Patient } \\
\text { characteristics }\end{array}$} & \multirow[b]{2}{*}{$\begin{array}{c}\text { Overall } \\
(n=\mathbf{4 5 , 0 8 2}) \\
\end{array}$} & \multicolumn{3}{|c|}{ Mitral valve surgery } & \multicolumn{3}{|c|}{ Mitral valve repair } & \multicolumn{3}{|c|}{ Mitral valve replacement } \\
\hline & & $\begin{array}{c}\begin{array}{c}\text { No history } \\
\text { of } \mathbf{H F} \\
(n=17,955)\end{array} \\
\end{array}$ & $\begin{array}{c}\text { History } \\
\text { of } \mathrm{HF} \\
(\mathrm{n}=\mathbf{2 7 , 1 2 7})\end{array}$ & $\begin{array}{c}P \\
\text { value }\end{array}$ & $\begin{array}{c}\text { No history } \\
\text { of } \mathbf{H F} \\
(n=8008)\end{array}$ & $\begin{array}{c}\begin{array}{c}\text { History } \\
\text { of } \mathbf{H F} \\
(\mathrm{n}=\mathbf{8 8 4 2})\end{array} \\
\end{array}$ & $\begin{array}{c}P \\
\text { value }\end{array}$ & $\begin{array}{c}\text { No history } \\
\text { of } \mathbf{H F} \\
(\mathrm{n}=9947)\end{array}$ & $\begin{array}{c}\text { History } \\
\text { of } \mathrm{HF} \\
(\mathbf{n}=\mathbf{1 8 , 2 8 5})\end{array}$ & $\begin{array}{c}P \\
\text { value }\end{array}$ \\
\hline Age, median y (IQR) & & $74(70-78)$ & $76(71-80)$ & .0001 & 73 (70-77) & $75(71-80)$ & .0001 & $74(70-78)$ & $76(71-80)$ & .0001 \\
\hline Female, $\%$ & 61 & 55 & 64 & .0001 & 47 & 60 & .0001 & 62 & 69 & .0001 \\
\hline White, $\%$ & 92 & 94 & 90 & .0001 & 95 & 91 & .0001 & 93 & 90 & .0001 \\
\hline Hypertension, \% & 52 & 50 & 54 & .0001 & 53 & 56 & .0001 & 48 & 53 & .0001 \\
\hline Diabetes, \% & 15 & 10 & 18 & .0001 & 9 & 15 & .0001 & 11 & 19 & .0001 \\
\hline Peripheral vascular disease, $\%$ & 3 & 2 & 3 & .0001 & 2 & 3 & .001 & 2 & 3 & .0001 \\
\hline $\begin{array}{l}\text { Stroke/transient ischemic } \\
\text { attack, } \%\end{array}$ & 8 & 7 & 9 & .0001 & 6 & 7 & .0001 & 8 & 9 & .0001 \\
\hline COPD, $\%$ & 18 & 10 & 22 & .0001 & 8 & 19 & .0001 & 12 & 24 & .0001 \\
\hline $\begin{array}{l}\text { History of respiratory } \\
\text { failure, } \%\end{array}$ & 10 & 5 & 14 & .0001 & 3 & 10 & .0001 & 6 & 15 & .0001 \\
\hline Renal failure, $\%$ & 8 & 4 & 11 & .0001 & 3 & 10 & .0001 & 4 & 12 & .0001 \\
\hline ESRD, \% & 1 & 1 & 2 & .0001 & 1 & 1 & .0001 & 1 & 2 & .0001 \\
\hline Atrial fibrillation, $\%$ & 49 & 30 & 61 & .0001 & 24 & 56 & .0001 & 35 & 63 & .0001 \\
\hline Anemia, $\%$ & 16 & 12 & 19 & .0001 & 12 & 18 & .0001 & 12 & 20 & .0001 \\
\hline Urgent admission status, $\%$ & 50 & 34 & 60 & .0001 & 28.0 & 53 & .0001 & 39 & 63 & .0001 \\
\hline
\end{tabular}

$H F$, Heart failure; $I Q R$, interquartile range; $C O P D$, chronic obstructive pulmonary disease; $E S R D$, end-stage renal disease.

$52.5 \%$ who underwent repair and $64.8 \%$ who underwent replacement. Atrial fibrillation was present in nearly half of the study cohort $(48.6 \%)$. Other major comorbidities included chronic obstructive pulmonary disease (COPD; $17.6 \%)$, renal failure including $\operatorname{ESRD}(8.2 \%)$, and diabetes $(14.7 \%)$. Overall, $49.5 \%$ of the procedures were performed during an urgent admission status.

Patients with a preoperative diagnosis of HF were slightly older (76 vs 74 years, $P=.0001$ ), had 2 times higher incidence of atrial fibrillation $(60.8 \%$ vs $30.1 \%$, $P=.0001)$, renal failure $(3.5 \%$ vs $11.2 \%, P=.0001)$, and ESRD ( $1.7 \%$ vs $0.8 \%, P=.0001)$, and were diagnosed 2.8 times more often with respiratory failure in the year preceding the index procedure $(13.5 \%$ vs $4.8 \%, P=.0001)$.

The incidence of all major preoperative comorbidities, including hypertension $(69.4 \%$ vs $49.8 \%)$, diabetes $(30.1 \%$ vs $14.7 \%)$, stroke/transient ischemic attack $(13.0 \%$ vs $7.4 \%)$, COPD (37.4\% vs $18.6 \%)$, respiratory failure $(19.8 \%$ vs $11.8 \%)$, renal failure $(20.7 \%$ vs $8.7 \%)$, and atrial fibrillation $(76.3 \%$ vs $56.7 \%)$ were higher in patients in whom preoperative HF was present for more than 3 months before surgery compared with those in whom the diagnosis was present for 3 months or less before the index operation $(P=.0001$ for all). An urgent operation was performed in $59.7 \%$ of patients with a preoperative diagnosis of HF compared with $34.1 \%$ of those without a preoperative diagnosis of HF $(P=.0001)$.

\section{Length of Stay}

In general, the median length of stay (LOS) of patients during hospitalization for MV surgery was 9 days (range, 7-15 days). Length of stay increased according to the presence and duration of HF and was 7 days (range, 6-11 days) for patients who did not have a diagnosis of chronic HF $(P=.0001), 11$ days (range, $7-16$ days) for patients with HF for 3 months or less and 12 days (range, 8-20 days) for patients with $\mathrm{HF}$ for 3 months or more $(P=.0001)$.

Within the subset of patients with preoperative HF, those who had HF for more than 3 months had a longer median LOS, but they also had a higher incidence of preoperative comorbidities. Therefore, we calculated the adjusted odds ratios (ORs) for LOS greater than the median according to duration of preoperative HF diagnosis (Table 2). After adjustment, patients with preoperative HF were still

TABLE 2. Impact of a history of preoperative heart failure in the year preceding surgery ( $\leq \mathbf{3}$ months and $>\mathbf{3}$ months) on length of stay greater than the median ( 8 days for repair, 10 days for replacement)

\begin{tabular}{|c|c|c|c|c|c|c|c|c|}
\hline & \multicolumn{4}{|c|}{$\mathrm{CHF} \leq \mathbf{3} \mathrm{mo}$} & \multicolumn{4}{|c|}{ CHF > 3 mo } \\
\hline & \multicolumn{2}{|c|}{ Unadjusted } & \multicolumn{2}{|c|}{ Adjusted } & \multicolumn{2}{|c|}{ Unadjusted } & \multicolumn{2}{|c|}{ Adjusted } \\
\hline & OR* & $95 \%$ CI & OR* & $95 \% \mathrm{CI}$ & $\mathbf{O R} *$ & $95 \% \mathrm{CI}$ & OR* & $95 \% \mathrm{CI}$ \\
\hline Repair & 2.84 & $2.66-3.03$ & 1.69 & $1.57-1.83$ & 3.50 & $3.13-3.90$ & 1.66 & $1.45-1.90$ \\
\hline Replacement & 2.66 & $2.52-2.81$ & 1.81 & $1.70-1.92$ & 3.11 & $2.88-3.35$ & 1.80 & $1.64-1.97$ \\
\hline
\end{tabular}

$\mathrm{CHF}$, Chronic heart failure; $O R$, odds ratio; $C I$, confidence interval. *Relative to no CHF 
TABLE 3. Impact of preoperative heart failure on operative mortality and long-term survival of Medicare beneficiaries undergoing mitral valve surgery: adjusted outcomes based on history of preoperative heart failure

\begin{tabular}{lcclcc}
\hline & \multicolumn{2}{c}{ Operative mortality } & & \multicolumn{2}{c}{ Long-term survival } \\
\cline { 2 - 3 } \cline { 5 - 6 } & OR & $\mathbf{9 5} \% \mathbf{C I}$ & & HR & $\mathbf{9 5 \%} \mathbf{C I}$ \\
\hline Mitral repair & 1.46 & $1.21-1.78$ & & 1.52 & $1.43-1.62$ \\
Mitral replacement & 1.36 & $1.23-1.51$ & & 1.36 & $1.31-1.42$ \\
\hline
\end{tabular}

This table compares the likelihood of adjusted operative mortality and long-term survival for patients with preoperative heart failure with those without preoperative heart failure. $O R$, Odds ratio; $C I$, confidence interval.

significantly more likely to have a LOS greater than the median both in the subset with HF for 3 months or less (OR, 1.69 for MVP; OR, 1.81 for MVR) and those with HF for more than 3 months (OR, 1.66 for MVP; OR, 1.80 for MVR).

\section{Operative Mortality and Long-Term Survival}

Unadjusted mortality. Hospital mortality increased with the presence of preoperative HF from $2.2 \%$ to $5.4 \%$ for repair and from $6.0 \%$ to $10.7 \%$ for replacement. Furthermore, the duration of preoperative HF increased operative risk. For repair, mortality for patients with HF of 3 months or less duration was $4.8 \%$, whereas the mortality for patients with HF of longer duration was $8.0 \%$. For replacement, these percentages were $9.5 \%$ and $14.6 \%$, respectively.

Adjusted mortality. As seen from Table 3, a preoperative diagnosis of HF had an adverse effect on the adjusted hospital mortality rates, both for patients undergoing repair (OR, 1.46; 95\% confidence interval [CI], 1.21-1.78) and for those undergoing replacement $(\mathrm{OR}, 1.36 ; 95 \% \mathrm{CI}$, 1.23-1.51). Furthermore, when we examined the effect of preoperative HF duration, we found that patients with HF for more than 3 months had higher adjusted operative mortality compared with those with preoperative HF for 3 months or less for the subset undergoing MVR (OR, 1.48; 95\% CI, 1.32-1.66); this effect also reached statistical significance for patients undergoing MVP (OR, 1.34; 95\% CI, 1.05-1.70).

Long-term survival. Long-term survival was also adversely affected by both the presence and the duration of preoperative HF (Table 4 and Figure 1). After adjustment for differences in baseline characteristics (other than HF), as well as admission status, a preoperative diagnosis of $\mathrm{HF}$ was still associated with a $52 \%$ and $36 \%$ increase in the risk of death over the 10-year follow-up for MVP and MVR patients, respectively (adjusted hazard ratio [HR], 1.52 [95\% CI, 1.43-1.62] for repair; adjusted HR, 1.36 [95\% CI, 1.31-1.42] for replacement). Thirty-day survival of patients who underwent repair and did not have a diagnosis of HF was $98 \%$, and their survival 1 year postoperatively remained almost the same as the general population ( $96 \%$ and $95 \%$, respectively). In both the repair and replacement groups, the greatest impact of preoperative HF on mortality was observed in the first postoperative year with the sharpest decrease in survival seen in those who underwent replacement.

When we examined the effect of preoperative HF duration, we found that patients with HF for 3 months or more had a $28 \%$ increased risk of death over the 10-year follow-up period regardless of whether they underwent MVP or MVR compared with those with preoperative HF for less than 3 months (adjusted HR, 1.28; 95\% CI, 1.181.39 for repair; adjusted HR, 1.27; 95\% CI, 1.22-1.34 for replacement). The impact of duration of HF became more evident during the subsequent years after the surgical intervention. In the repair group, survival of patients with $\mathrm{HF}$ for 3 months or less was $88.6 \%$ at the end of the first postoperative year compared with $81.9 \%$ for those with HF for 3 months or more; however, this difference was more prominent at the end of 10 years when $46.7 \%$ of the first group were still alive but survival was only $27.6 \%$ for those with a diagnosis of HF for more than 3 months preoperatively. The same was true for patients who underwent replacement: the 1-year survival of patients with HF for 3 months or less was $81.3 \%$ compared with $71.8 \%$ among those with HF for more than 3 months; by 10 years after the surgical intervention, $34.2 \%$ of those with HF for 3 months of less were still alive compared with $19.6 \%$ of those who had HF for more than 3 months.

\section{DISCUSSION}

The influence of preoperative symptoms on postoperative outcomes of patients undergoing MV surgery has been examined in several studies. ${ }^{5,6}$ A study on the long-term outcomes of 478 patients with organic MR undergoing surgical correction demonstrated that patients with preoperative New York Heart Association (NYHA) class III/IV

TABLE 4. Impact of history of chronic heart failure in year preceding surgery ( $\leq 3$ months and $>3$ months) on long-term survival

\begin{tabular}{|c|c|c|c|c|c|c|c|c|}
\hline & \multicolumn{4}{|c|}{$\mathrm{CHF} \leq \mathbf{3} \mathrm{mo}$} & \multicolumn{4}{|c|}{$\mathrm{CHF}>3 \mathrm{mo}$} \\
\hline & \multicolumn{2}{|c|}{ Unadjusted } & \multicolumn{2}{|c|}{ Adjusted } & \multicolumn{2}{|c|}{ Unadjusted } & \multicolumn{2}{|c|}{ Adjusted } \\
\hline & $\mathbf{H R}^{*}$ & $95 \% \mathrm{CI}$ & HR* & $95 \%$ CI & HR* & 95\% CI & HR* & 95\% CI \\
\hline Repair & 2.00 & $1.88-2.13$ & 1.47 & $1.38-1.57$ & 3.42 & $3.14-3.72$ & 1.88 & $1.71-2.07$ \\
\hline Replacement & 1.62 & $1.56-1.69$ & 1.31 & $1.25-1.36$ & 2.54 & $2.42-2.67$ & 1.66 & $1.57-1.76$ \\
\hline
\end{tabular}

$\mathrm{CHF}$, Chronic heart failure; $H R$, hazard ratio; $C I$, confidence interval. *Relative to no CHF. 


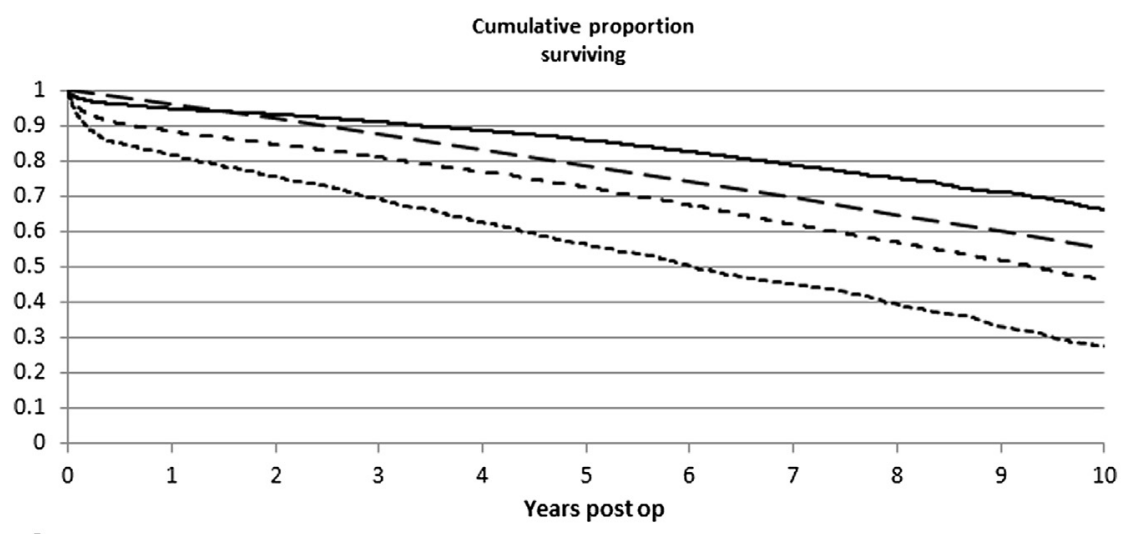

A $-\mathrm{CHF}-\quad---\mathrm{CHF}<=3$ months $\quad----$ CHF $>3$ months $\quad-$ - Expected

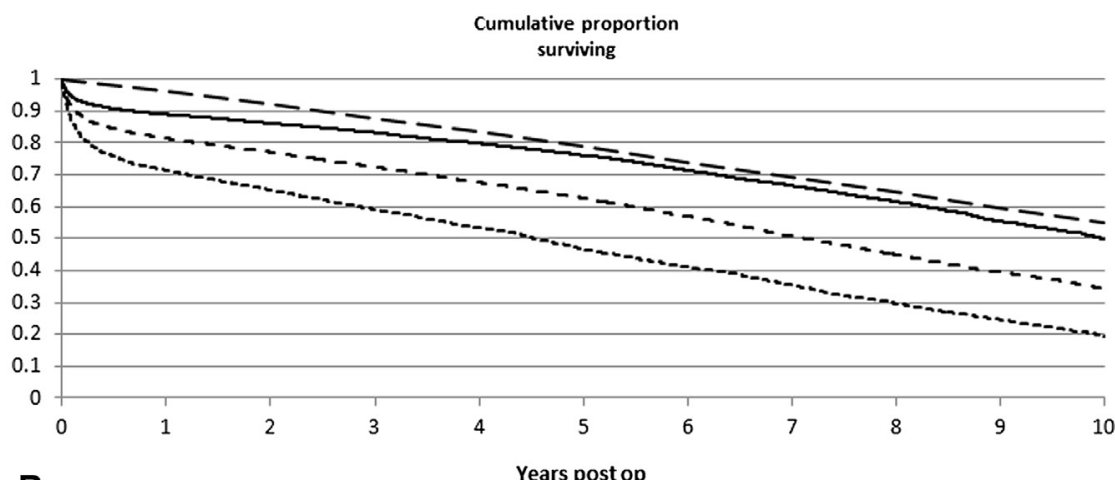

B $\quad$ CHF - $\quad--\mathrm{CHF}<=3$ months $\quad---$. CHF $>3$ months $\quad-\quad$ Expected

FIGURE 1. Survival after mitral valve surgery by history and duration of preoperative heart failure. A, Repair subset; B, replacement subset. $\mathrm{CHF}$, Chronic heart failure.

symptoms had higher operative mortality $(5.4 \%$ vs $0.5 \%$, $P=.003)$ and lower 10 -year survival $(48 \% \pm 4 \%$ vs $76 \% \pm 5 \%, P<.0001)$ compared with patients with NYHA class I/II symptoms, and this excess mortality was confirmed in multivariate analysis, adjusting for other independent predictors of outcome including age and ejection fraction. ${ }^{5}$ Furthermore, although severely symptomatic patients had an increased rate of death because of left ventricular (LV) dysfunction, their excess risk occurred independently of preoperative LV function. In contrast to this elegant analysis in which the mean age of the patient cohort was 65 years, preoperative symptoms were not found to be a poor predictor of outcomes in a small study that focused on elderly patients with a mean age of 78 years. ${ }^{6}$ It has been suggested that large population datasets are required to properly analyze this complex issue but these were lacking in most previous studies and may explain the inconsistencies in earlier results. ${ }^{5}$ This may be particularly relevant in the elderly, who are typically underrepresented in most series of patients undergoing MV surgery. We conducted a retrospective analysis of a large cohort of Medicare beneficiaries who underwent MVP or MVR from 2000 to 2009 to examine the impact of preoperative HF on operative mortality and long-term survival in this patient population. We hypothesized that a diagnosis of HF adversely affects the outcomes in the elderly, and that a longer duration of HF is likewise associated with worse outcomes in these patients.

We found that among elderly patients undergoing primary isolated MVP and MVR, the presence of a preoperative diagnosis of HF in the year preceding surgery was associated with significantly higher hospital mortality and worse long-term survival. Among patients undergoing MVP and MVR, a preoperative diagnosis of HF was associated with a $46 \%$ and $36 \%$ increased risk of operative mortality, and a $52 \%$ and $36 \%$ increase in the risk of death over a 10-year follow-up period, respectively. Furthermore, the duration of preoperative HF adversely affected operative mortality and long-term survival irrespective of procedure type (repair or replacement). Because mitral repair is associated with better preservation of ventricular function, we postulate that this benefit may have counteracted the impact of preoperative HF duration on operative mortality for patients who underwent repair. Another important finding of our investigation was that the LOS increased according to the presence of preoperative 
HF, even after adjustment for significant baseline characteristics. This has significant cost implications in an overburdened heath care system.

The impact of preoperative HF must be examined in the context of the bigger issue of the risk-benefit analysis for surgery in elderly patients with MV disease. Although current guidelines recommend a conservative approach for the elderly unless severely symptomatic, recent work has challenged the assumptions about negative surgical outcomes based on age alone., ${ }^{2,3,7,8}$ MV surgery in the Medicare population carries less risk than previously reported; the operative mortality for repair is $3.9 \%$ and $8.9 \%$ for replacement. ${ }^{3}$ Nevertheless, the perceived uncertainty regarding surgical outcomes in the elderly along with the larger issue of nonadherence to MV guidelines has led to significant under-referral for surgery among elderly patients. In a large European multicenter study by Mirabel and colleagues, ${ }^{9} 49 \%$ of symptomatic patients with severe MR were denied surgery and advanced age was identified as one of the main reasons for the decision to not operate. Among patients aged 70 to 80 years, 58\% of those with symptoms were not referred to surgery and in those aged 80 years and older, this percentage rose to $85 \%$. Suboptimal adherence to MV guidelines is not unique to Europe. A recent survey of Canadian cardiologists suggests that there is variation in referral patterns and that the overall compliance with ACC/AHA guidelines was only $66 \% .{ }^{10}$ Similarly, another study showed that compliance could also be optimized among American cardiologists. ${ }^{11}$ In a study by Bach and colleagues, ${ }^{12} 74 \%$ of patients with severe MR and at least 1 guideline indication for surgery did not receive an operation despite a preoperative risk profile that was not prohibitive on an objective assessment.

Elderly patients present for MV surgery with worse preoperative profiles and, consequently, have worse outcomes compared with younger patients. ${ }^{13}$ As a result, underreferral or delayed referral to MV surgery may disproportionally affect the elderly, despite high-quality studies documenting excellent surgical outcomes and pronounced benefits postoperatively. ${ }^{13}$ In addition to our own work, Tribouilloy's group have suggested that, as a result of recent improvements in surgical techniques and outcomes, elderly patients should be carefully considered for surgical intervention before the onset of refractory HF. ${ }^{5} \mathrm{HF}$ accounts for a significant number of deaths in the elderly,${ }^{14}$ in addition to an increased number of hospital admissions postoperatively and a diminished quality of life. Therefore, a decision to defer surgical referral for MV disease solely based on advanced age discounts the benefits of timely surgery and the risks of nonsurgical management, including HF and death. ${ }^{15-17}$

In addition to the large proportion of patients with preoperative $\mathrm{HF}$, the delay in surgical referral was evident from the fact that half of these elderly patients undergoing MV surgery were operated urgently. This seems counterintuitive to what one would expect to see in a cohort of patients of advanced age. As the incidence of comorbidities increases with age, thereby increasing the perioperative risk in the elderly, ideally, surgical intervention should be offered under the best possible circumstances, that is, electively with strict preoperative optimization. The factors responsible for this finding are unclear and may be due either to a delay in the diagnosis of MV disease in the elderly or a bias to delay referral to surgery in this patient population.

Our findings suggest that significant improvements in surgical outcomes in the elderly with MV disease, particularly before development of HF, coupled with the lack of established medical treatment should encourage surgical referral in the elderly based on objective data and individualized risk assessment, weighing the benefits of early surgery against the consequences of no surgical intervention in these patients.

Our study has several noteworthy limitations. It is a retrospective analysis with all of its inherent limitations. We have used administrative claims data, which may be limited by erroneous coding. Nevertheless, the Medicare database has been used extensively to study cardiovascular outcomes. ${ }^{18,19}$ Of particular importance for this study is the lack of ventricular function information, which may have shed further light into the association of preoperative HF and MV surgical outcomes. Despite these limitations, our study focused on a large population of elderly patients and adds to the body of literature that, thus far, has included smaller studies and younger patient populations. In our cohort, surgery was performed at a variety of hospitals participating in Medicare. Therefore, our findings may be more widely generalizable compared with those of single high-volume centers.

In conclusion, preoperative $\mathrm{HF}$ is present in a large number of elderly patients undergoing primary isolated MV surgery. The presence of HF preoperatively adversely affects short-term and long-term survival, irrespective of the type of procedure (repair or replacement). The study supports the early identification of elderly patients with MV disease and referral to surgery before the onset of HF.

\section{References}

1. Nkomo VT, Gardin JM, Skelton TN, Gottdiener JS, Scott CG, EnriquezSarano M. Burden of valvular heart diseases: a population-based study. Lancet 2006;368:1005-11.

2. Bonow RO, Carabello BA, Chatterjee K, de Leon AC Jr, Faxon DP, Freed MD, et al. American College of Cardiology/American Heart Association Task Force on Practice Guidelines. 2008 focused update incorporated into the ACC/AHA 2006 guidelines for the management of patients with valvular heart disease: a report of the American College of Cardiology/American Heart Association Task Force on Practice Guidelines (Writing Committee to revise the 1998 guidelines for the management of patients with valvular heart disease). Endorsed by the Society of Cardiovascular Anesthesiologists, Society for Cardiovascular Angiography and Interventions, and Society of Thoracic Surgeons. J Am Coll Cardiol. 2008;52:e1-142. 
3. Vassileva CM, Mishkel G, McNeely C, Boley T, Markwell S, Scaife S, et al. Long term survival of patients undergoing mitral valve repair and replacement: a longitudinal analysis of Medicare fee-for-service beneficiaries. Circulation. 2013; 127:1870-6.

4. Arias E. United States Life Tables, 2007. National Vital Statistics Reports; Vol. 59, no. 9. Hyattsville, MD: National Center for Health Statistics; 2011.

5. Tribouilloy CM, Enriquez-Sarano M, Schaff HV. Impact of preoperative symptoms on survival after surgical correction of organic mitral regurgitation: rationale for optimizing surgical indications. Circulation. 1999;99:400-5.

6. Ailawadi G, Swenson BR, Girotti ME, Gazoni LM, Peeler BB, Kern JA, et al. Is mitral valve repair superior to replacement in elderly patients? Ann Thorac Surg. 2008;86:77-85; discussion 86.

7. Rao RK, Foster E. Rethinking mitral valve surgery during the golden years. Circulation. 2013;127:1843-6.

8. Badhwar V, Peterson ED, Jacobs JP, He X, Brennan JM, O’Brien SM, et al. Longitudinal outcome of isolated mitral repair in older patients: results from 14,604 procedures performed from 1991 to 2007. Ann Thorac Surg. 2012;94:1870-7.

9. Mirabel M, Iung B, Baron G, Messika-Zeitoun D. What are the characteristics of patients with severe, symptomatic, mitral regurgitation who are denied surgery? Eur Heart J. 2007;28:1358-65.

10. Toledano K, Rudski LG, Huynh T, Béique F, Sampalis J, Morin J-F. Mitral regurgitation: Determinants of referral for cardiac surgery by Canadian cardiologists. Can J Cardiol. 2007;23:209-14.

11. Harris KM, Pastorius CA. Practice variation among cardiovascular physicians in management of patients with mitral regurgitation. Am J Cardiol. 2009;103: 255-61.
12. Bach DS, Awais M, Gurm HS, Kohnstamm S. Failure of guideline adherence for intervention in patients with severe mitral regurgitation. J Am Coll Cardiol. 2009; $54: 860-5$.

13. Detaint D, Sundt TM, Nkomo VT, Scott CG, Tajik AJ, Schaff HV, et al. Surgical correction of mitral regurgitation in the elderly: outcomes and recent improvements. Circulation. 2006;114:265-72.

14. Ling LH, Enriquez-Sarano M, Seward JB, Tajik AJ, Schaff HV, Bailey KR, et al Clinical outcome of mitral regurgitation due to flail leaflet. $N$ Engl J Med. 1996; 335:1417-23.

15. Kochanek KD, Xu J, Murphy SL, Minino AM, Kung H-C. Deaths: Final Data for 2009. National Vital Statistics Reports; Vol. 60, no. 3. Hyattsville, MD: National Center for Health Statistics; 2012.

16. Delahaye JP, Gare JP, Viguier E, Delahaye F, De Gevigney G, Milon H. Natural history of severe mitral regurgitation. Eur Heart J. 1991;12(Suppl B):5-9.

17. Suri RM, Vanoverschelde JL, Grigioni F, Schaff HV, Tribouilloy C, Avierinos JF, et al. Association between early surgical intervention vs watchful waiting and outcomes for mitral regurgitation due to flail mitral valve leaflets. JAMA 2013;310:609-16.

18. Krumholz HM, Wang Y, Mattera JA, Wang Y, Han LF, Ingber MJ, et al. An administrative claims model suitable for profiling hospital performance based on 30-day mortality rates among patients with an acute myocardial infarction. Circulation. 2006;113:1683-92.

19. Krumholz HM, Wang Y, Mattera JA, Wang Y, Han LF, Ingber MJ, et al. An administrative claims model suitable for profiling hospital performance basec on 30-day mortality rates among patients with heart failure. Circulation. 2006; 113:1693-701. 